\title{
Integral Characteristics of Hydrogen Production in Alkaline Electrolysers
}

\author{
Mitja Mori* - Tilen Mržljak - Boštjan Drobnič - Mihael Sekavčnik \\ University of Ljubljana, Faculty of Mechanical Engineering, Slovenia
}

\begin{abstract}
This paper summarises the results of experimental investigations of a commercial alkaline water electrolyser used for hydrogen production to balance decentralised electricity production from renewables. Experiments have been conducted on an alkaline water electrolyser operating at a pressure range up to 25 bar g and having a maximum production capacity of $15 \mathrm{Nm}^{3}$ hydrogen per hour. In stationary conditions, the energy efficiency of an electrolytic cell has been calculated, and the characteristics of the electrolyser stack has been described with an empirical equation. The energy efficiency of the entire system and hydrogen losses within the boundaries of the system have been determined. Experimental results show that the energy efficiency of an electrolytic cell at typical operating conditions ranges between 73 and $83 \%$, and the energy efficiency of the entire system is between 50 and $60 \%$. Hydrogen losses within the boundaries of the system, compared to the total produced amount of hydrogen, are between 10 and 25\%, depending of operating conditions.
\end{abstract}

Keywords: advanced energy systems, renewable energy sources, alkaline water electrolysis, hydrogen production, energy characteristics

\section{O INTRODUCTION}

Renewable energy sources (RES) will play a crucial role in the world's future energy supply. However, prior to their large-scale integration into the existing infrastructure, certain challenges have to be addressed.

One of the main challenges is associated with the somewhat unpredictable and fluctuating nature of wind and solar energy sources, which can cause imbalances between the production and consumption of electrical energy in the grid, [1] and [2]. These inconsistencies in supply (due to the stochastic nature of renewable energy sources) and forecasting difficulties can be reduced to a certain extent by different (electrical) energy storage systems, [3] and [4]. Energy storage systems enable power-supply reliability and quality as well as system stability. Pumped-storage hydroelectric power plants maintain the balance between the supply and demand of electricity in the transmission network, while renewable energy sources (except large hydroelectric power plants) are usually connected to the distribution network, [4]. Energy storage based upon converting electrical energy to chemical (internal) energy of hydrogen and back is foreseen as one possible solution to this problem, [3] and [5].

Hydrogen is proposed as an energy-efficient pathway. Therefore, it is recognised as one of the energy carriers of the future, [5]. An electrolyser using electricity to generate hydrogen from water, a hydrogen storage tank and a fuel cell that recombines hydrogen with oxygen to generate electricity would be the main components of the so-called hydrogen infrastructure, which would balance the production and consumption of electrical energy in the distribution network (Fig. 1).

A demonstration laboratory for the simulation of advanced energy systems has been constructed at the hydrogen production site on the location of Šoštanj Thermal Power Plant (TEŠ). The primary aim of this project is to use technologically-advanced hydrogen production and logistics solutions in the design and demonstration of an advanced energy supply system that uses renewable energy sources and enables the optimisation of the performance of existing energy sources, [6]. This paper summarises the first stage of this project, whose main objective was to experimentally investigate the operational and energy characteristics of a commercial electrolyser and evaluate its role in advanced energy supply systems.

\section{THEORETICAL PRINCIPLES OF WATER ELECTROLYSIS}

The splitting of water into gaseous hydrogen and oxygen by the action of electricity can be expressed as, [7]:

$$
\mathrm{H}_{2} \mathrm{O}(\mathrm{l})+2 \mathrm{~F} \rightarrow \mathrm{H}_{2}(\mathrm{~g})+1 / 2 \mathrm{O}_{2}(\mathrm{~g}),
$$

where $F$ is the Faraday constant representing the magnitude of electric charge per mole of electrons (96487 As/mol, [8]). Eq. (1) shows that water electrolysis is an extremely clean process, since no polluting by-products are formed. However, it should not be forgotten that a technology cannot be cleaner than the energy source used to power it, [7]. A definite advantage of electrochemical technology is its reversibility. The reverse of the above reaction (Eq. (1)) occurs in an $\mathrm{H}_{2}-\mathrm{O}_{2}$ fuel cell, [7]: 
hydrogen infrastructure

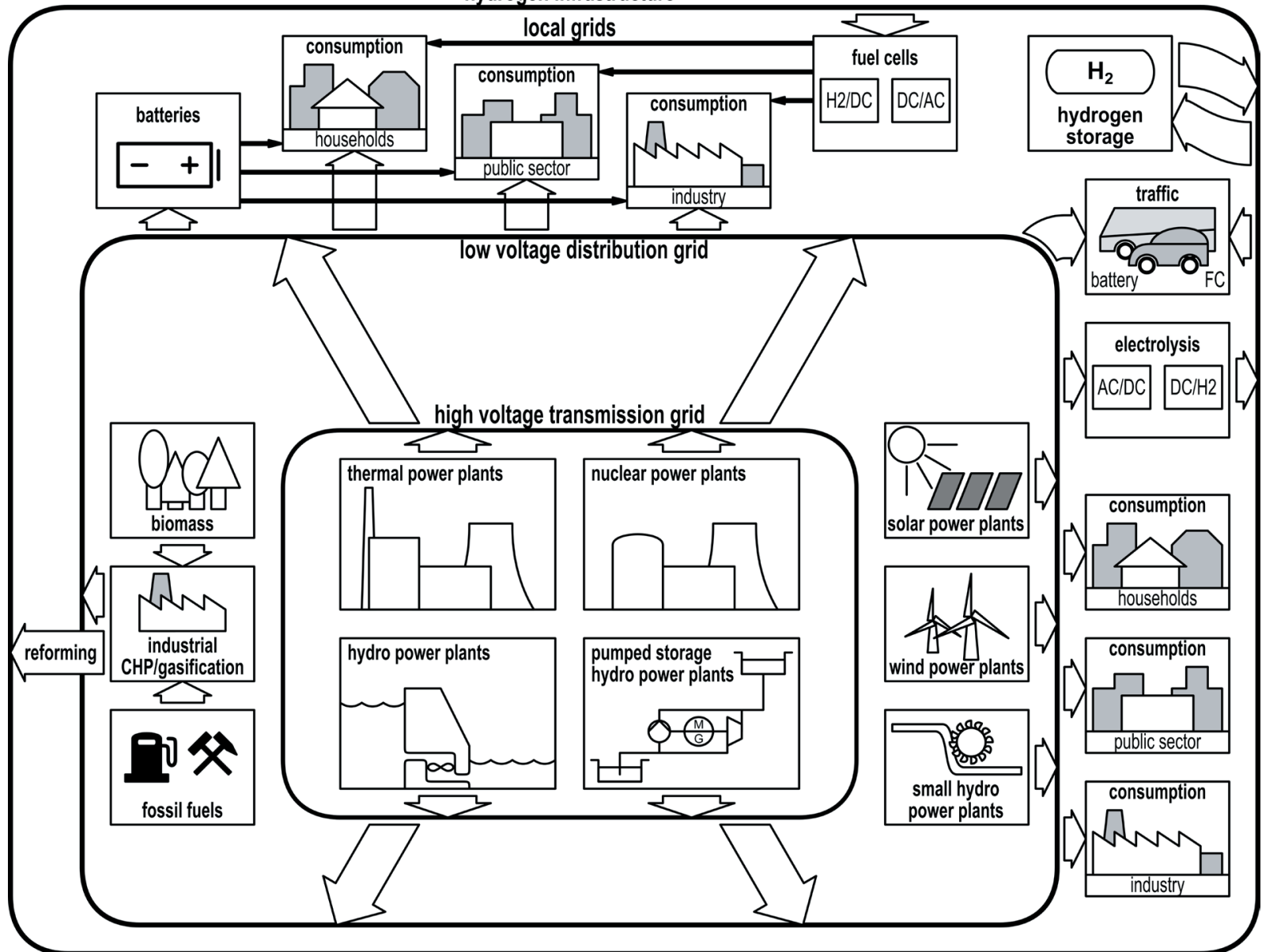

Fig. 1. The idea of hydrogen infrastructure integration into conventional power system

$$
\mathrm{H}_{2}(\mathrm{~g})+1 / 2 \mathrm{O}_{2}(\mathrm{~g}) \rightarrow \mathrm{H}_{2} \mathrm{O}(\mathrm{l})+2 F .
$$

The quantity of a substance altered at an electrode during electrolysis can be calculated according to Faraday's (first) law of electrolysis, [9]:

$$
\dot{m}_{\mathrm{p}}=\frac{d m_{\mathrm{p}}}{d t}=\frac{M_{\mathrm{p}}}{v_{\mathrm{e}} \cdot F} \cdot I \text {. }
$$

The mass flow of the product $\left(\dot{m}_{\mathrm{p}}\right)$ is directly proportional to the electric current $(I)$ running through the electrolytic cell. Other terms in the expression correspond to the Faraday constant $(F)$, stoichiometric coefficient (required number of moles of electrons for the formation of one mole of product; oxygen: $v_{\mathrm{e}}=4$; hydrogen: $v_{\mathrm{e}}=2$ ) and the molar mass of the product (oxygen: $M_{\mathrm{p}}=32.0 \mathrm{~g} \mathrm{~mol}^{-1}$; hydrogen: $M_{\mathrm{p}}=2.02 \mathrm{~g}$ $\left.\mathrm{mol}^{-1},[8]\right)$.

An electrochemical system is in equilibrium when the following condition is met, [10]:

$$
\Delta G=z \cdot F \cdot U_{\text {rev }},
$$

where $\Delta G$ represents the change in Gibbs energy, $z$ is the number of moles of electrons transferred in the reaction (for water electrolysis $z=2$ ) and $U_{\text {rev }}$ is the reversible (cell) voltage, which is the minimum voltage needed to drive the water-splitting reaction (and also the maximum amount of useful work that can be derived from the system when driving the reaction in the opposite direction; Eq. (2)), [11]. At standard conditions $\left(T=25{ }^{\circ} \mathrm{C}\right.$ and $\left.p=101.3 \mathrm{kPa},[8]\right)$, the reversible voltage is equal to $1.23 \mathrm{~V}\left(\Delta G^{0}=237.0 \mathrm{~kJ}\right.$ $\left.\mathrm{mol}^{-1},[8]\right)$.

However, at this voltage (and conditions), the water-splitting reaction is endothermic; hence, for isothermal operation heat must be absorbed from the surrounding environment. The total amount of energy needed in water electrolysis is equivalent to the change in enthalpy $(\Delta H)$, which differs from $\Delta G$ by the entropic term $T \cdot \Delta S,[9]$ : 


$$
\Delta G=\Delta H-T \cdot \Delta S .
$$

The entropic term $T \cdot \Delta S$ represents thermal irreversibility, which for a reversible process is equal to the heat demand. The voltage corresponding to the total energy demand $(\Delta H)$, the thermo-neutral (cell) voltage $\left(U_{\mathrm{tn}}\right)$ is given by the equation, [10]:

$$
\Delta H=z \cdot F \cdot U_{\mathrm{tn}} .
$$

At standard conditions, the thermoneutral voltage is equal to $1.48 \mathrm{~V}\left(\Delta H^{0}=285.5 \mathrm{~kJ} \mathrm{~mol}^{-1}\right.$, [8]). When the electrolytic cell is operated above $U_{\mathrm{tn}}$, the reaction becomes exothermic, and heat must be removed from the cell for isothermal operation (Fig. 2).

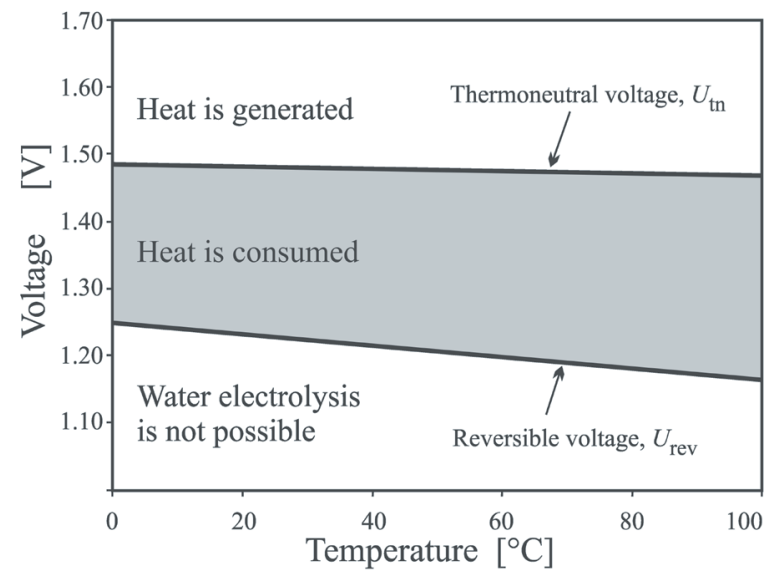

Fig. 2. Reversible and thermo-neutral voltage for water electrolysis as a function of temperature at a pressure of 1 bar

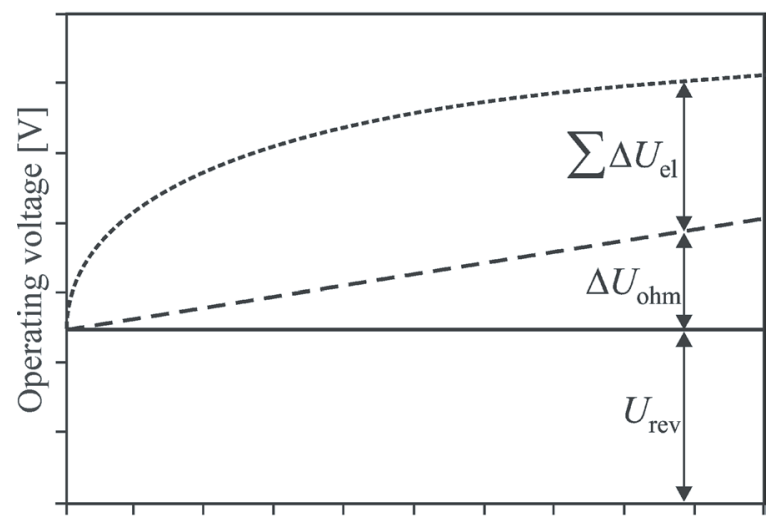

Electric current $[\mathrm{A}]$

Fig. 3. Contribution of individual (over)voltage to the operating (actual) voltage of the electrolytic cell, [7]

Due to the energy losses associated with reaction kinetics as well as charge transport through electrical leads and the electrolyte, all practical devices for water electrolysis operate in a voltage regime that is above the thermoneutral voltage. The operating or actual voltage $\left(U_{\mathrm{op}}\right)$ of an electrolytic cell can be expressed as, [7], [11]:

$$
U_{\mathrm{op}}=U_{\mathrm{rev}}+\sum \Delta U_{\mathrm{el}}+\Delta U_{\mathrm{ohm}}+\Delta U_{\mathrm{t}}
$$

The overvoltage (the voltage in excess of the $\left.U_{\text {rev }}\right)$ can be divided into three categories. The term $\Sigma \Delta U_{\text {el }}$ represents the sum of the anodic and cathodic overpotentials. It arises as a result of several polarisation effects, including low activity of the electrodes in the electrolyte (known as 'activation overpotential'). The electrode overpotential increases logarithmically (Fig. 3) with current density $(j)$ as given by the Tafel relation, [11]:

$$
\Delta U=a+b \cdot \ln (j),
$$

where $a$ and $b$ are characteristic constants for the electrode system. The electrode overpotential can be minimised by selecting electrode materials with high electro-catalytic activity, and maximum realto-apparent surface area as well as by operating the process at elevated temperatures (enhances the reaction rate) and pressures. In contrast, managing the process at higher current densities, which are associated with higher production rates (Eq. (3)), increases overvoltages (Eq. (8)).

The term $\Delta U_{\text {ohm }}$ represents the energy dissipation related to ohmic drops in the electrolytic cell that occur mainly at the electrodes, electrical lead wires, metalmetal joints, and inside the electrolyte. Optimisation of the cell design, i.e. minimising the distance between the electrodes and reducing the electrolyteresistance, lowers the ohmic overvoltage. An increase in operating temperature also helps to reduce $\Delta U_{\text {ohm }}$ as it decreases the electrolyte resistance, [7] and [11]. This category of overvoltage changes according to Ohm's law (Fig. 3):

$$
\Delta U_{\mathrm{ohm}}=R \cdot I .
$$

The last term in Eq. (7) is $\Delta U_{\mathrm{t}}$, which expresses a phenomenological observation that the operating voltage applied to an electrolytic cell (at constant operating conditions; $T, p$ and $I$ ) tends to increase with time as a consequence of performance degradation. The latter can be due to a loss of activity of electrode materials (surface wear) as well as an increase in ohmic drops (decrease in electrolyte concentration, loosening of electrical connections), [7]. Overvoltage minimisation is essential for the high efficiency operation of the electrolytic cells. 
The contribution of mass concentration overvoltage is not shown in Fig. 3, since it would become apparent only at some point outside the voltages tested here.

Three process versions have been developed for water electrolysis: alkaline water electrolysis, membrane water electrolysis (also SPE water electrolysis or PEM water electrolysis) and hightemperature (steam) electrolysis, [9] and [14].

\section{EXPERIMENTS}

Experiments have been conducted on a commercial alkaline water electrolysis system, which was initially acquired (and designed) for the needs of the Šoštanj thermal power plant for hydrogen (cooling of electric generators) and oxygen (welding) production. The alkaline electrolyser went into operation in 2006. A programmable logic controller (PLC), a computer and a fuel cell were added to the existing water electrolysis system and hydrogen storage tank. The primary aim of the first stage of the project was to investigate operational and energy characteristics, as well as the limitations of the water electrolyser before connecting all the elements into a system of advanced energy supply.

The analysed commercial alkaline electrolyser presented in Fig. 4 operates at a pressure range up to 25 bar $\mathrm{g}$ and has a maximum production capacity of $15 \mathrm{Nm}^{3}$ hydrogen per hour. The cell stack consists of a series of 90 interconnected, circular electrolysis cells (each cell has an electrode area of $0.2463 \mathrm{~m}^{2}$ ) arranged in a bipolar configuration. The basic parts are assembled and compressed in a unique and patented way, following the filter press system (zerogap geometry). A 30\% aqueous solution of potassium hydroxide $(30 \% \mathrm{KOH})$ is used as the electrolyte. The produced hydrogen has a nominal purity of $99.998 \%$, and the hydrogen storage tank has a volume of $20 \mathrm{~m}^{3}$, [12]. In comparison to a typical alkaline water electrolysis system, it has two distinctive features, [12]:

- demineralised water is fed to the system by gravity via an intermediate buffer (called 'Fill Up Volume' - Fig. 4), which is cyclically pressurised by the pressure of the system (valves are switched

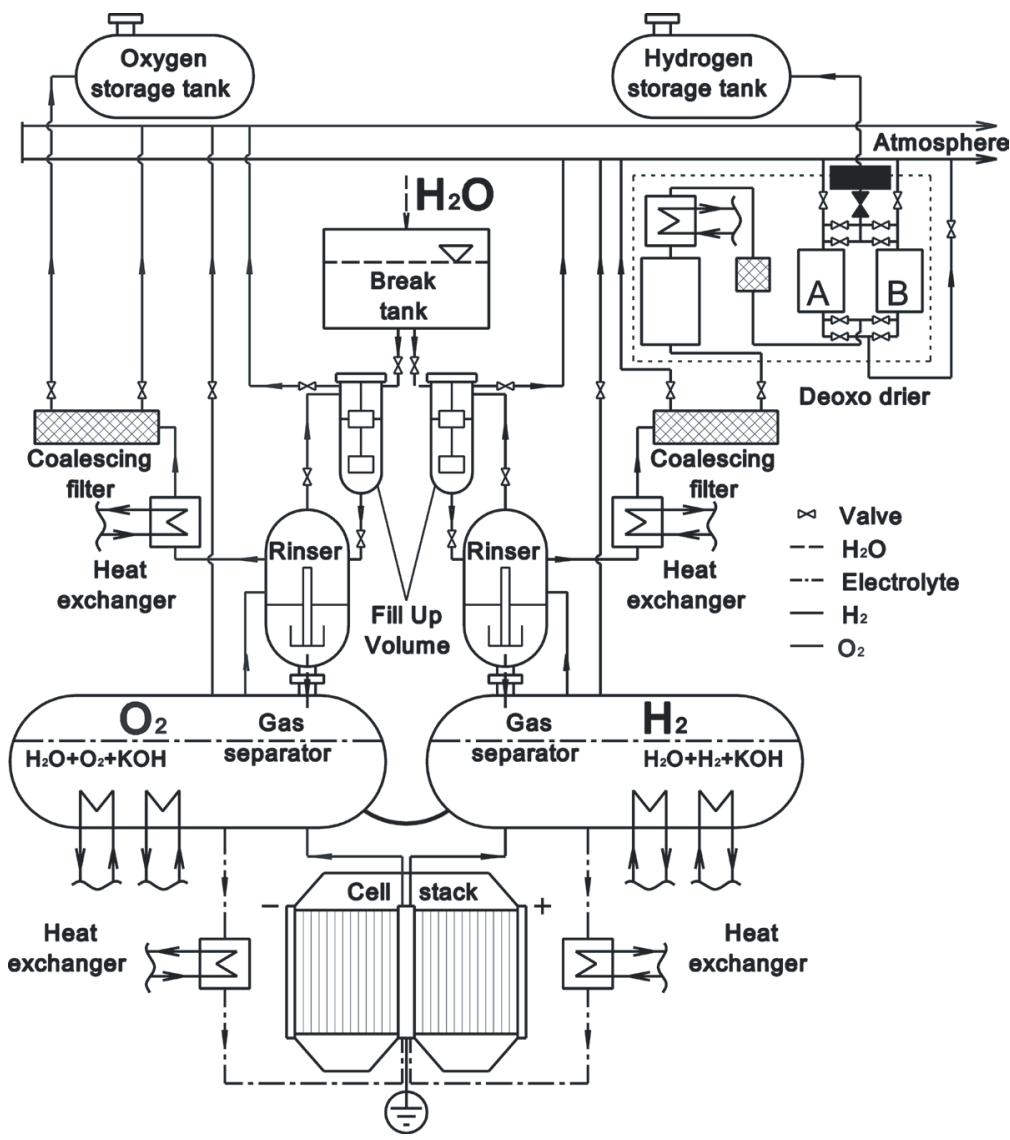

Fig. 4. Simplified schematic of the analyzed commercial alkaline electrolyzer, [12] 
in a certain sequence), so there is no need for a demineralised water feed pump, and

- the special design of the cell stack enables the circulation of the electrolyte without the use of an electrolyte (circulation) pump.

An advantage of this configuration is that the system has lower electrical load, thereby contributing to a lower consumption of electricity. However, the operation of the Fill Up Volume buffer involves hydrogen losses, which have a negative impact on the overall energy efficiency of the system.

\subsection{Experimental Procedure}

Signals from twenty-one (21) sensors installed in the system provide data regarding temperature (cell stack, deoxo drier, cooling system, process room, electrical room), gauge pressure (hydrogen storage tank line, cooling system, gas separator), electrolyte level (oxygen and hydrogen gas separator), electrical voltage (cell stack, UPS), electric current (cell stack), electrical conductivity (feed water), volume percentage of hydrogen in oxygen (coalescing filter for oxygen) and electricity consumption (hydrogen production site). During the experiments, the ambient temperature and pressure, the temperature in hydrogen storage tank and the experimental time were also monitored.

During electrolyser operation, two parameters can be varied: electric current (in our case between 180 and $400 \mathrm{~A}$, where $400 \mathrm{~A}$ corresponds to the nominal production of hydrogen; $15 \mathrm{Nm}^{3}$ per hour), which is proportional to the production of hydrogen (Eq. (3)) and the position of the back pressure regulator (BPR in Fig. 4), which regulates gauge pressure in the system and was between 12 and 21 bar g in our case. The operating temperature of the process (electrolyte temperature) is predefined and locked by the manufacturer. During the experiments, it varied in a range from 59 and $65^{\circ} \mathrm{C}$.

Two main sets of measurements were concluded, and are presented in experimental matrix in Fig. 5. In the first set (experiments BPRi), the position of the BPR was fixed (BPR1, BPR2, BPR3 in Fig. 5) and the electric current was varied. At a single position of the BPR, four measurements at different electric currents were made. The measurement at an experimental point lasted 20 minutes and the entire experiment 5 hours. The second set of measurements (experiments pCONST) were made with a variation of both the position of the BPR and the electric current. The position of the BPR was varied to achieve constant pressure in the system (p16, p18, p20 in Fig. 5).
According to the analysis of the BPRi experiments, the duration of a single measurement point was shortened to 5 or 10 minutes. The entire experiment lasted 4 hours and 40 minutes.

The data from 20 sensors were automatically recorded every 30 seconds. In the case of electricity consumption, ambient temperature and pressure and temperature in hydrogen storage tank measurement data were collected manually at the beginning and at the end of individual sets of measurements to obtain the integral value of each observed parameter.

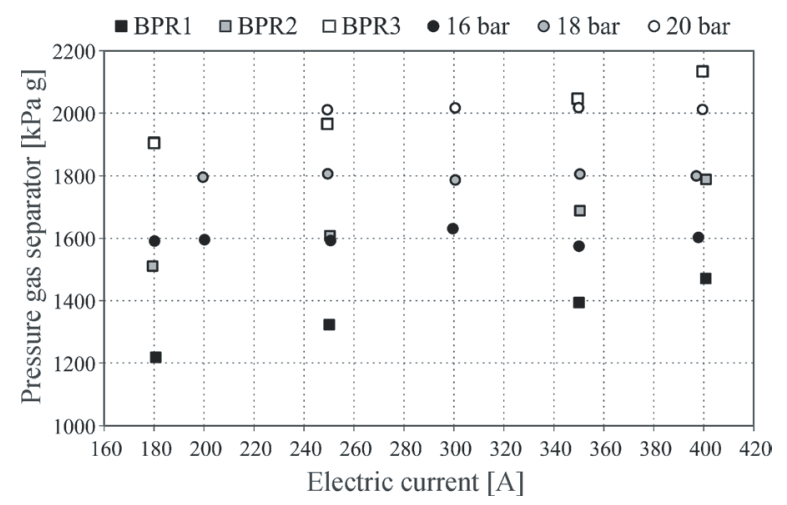

Fig. 5. Experimental matrix of operating conditions during experiments

\section{RESULTS}

On the basis of experimental data and the alkaline water electrolysis system specifications and limitations, the following calculations have been performed:

- energy efficiency of an electrolytic cell, $\eta_{\mathrm{c}}$,

- constants of the empirical $I-U$ model,

- energy efficiency of the entire system, $\eta$, and

- hydrogen losses within the boundaries of the system, $\xi$.

\subsection{Energy Efficiency of an Electrolytic Cell}

The energy efficiency of an electrolytic cell can be calculated as:

$$
\eta_{\mathrm{c}}=\frac{\dot{H}_{\mathrm{H}_{2}, \mathrm{c}}}{P_{\mathrm{ele}, \mathrm{c}}}=\frac{\eta_{\mathrm{F}} \cdot \dot{m}_{\mathrm{H}_{2}, \mathrm{c}} \cdot H_{\mathrm{S}, \mathrm{H}_{2}}}{U_{\mathrm{op}} \cdot I},
$$

where $\eta_{\mathrm{F}}$ is the faradaic efficiency (also known as current efficiency) defined as the ratio between the actual and theoretical maximum amount of hydrogen produced in an electrolytic cell, $\dot{m}_{\mathrm{H} 2, \mathrm{c}}$ is the theoretical mass flow of hydrogen produced in an electrolytic cell (Eq. (3)), $H_{\mathrm{S}, \mathrm{H} 2}$ is the higher heating value (HHV) 
of hydrogen, and $I$ is the electric current. Further derivation of Eq. (10) shows that $\eta_{\mathrm{c}}$ can also be written as, [12]:

$$
\eta_{\mathrm{c}}=\eta_{\mathrm{F}} \cdot \frac{U_{\mathrm{tn}}}{U_{\mathrm{op}}}
$$

Since there is no sensor for hydrogen mass flow measurement installed in the system, it was assumed that the hydrogen mass flow from an electrolytic cell is equal to $m_{\mathrm{H} 2, \mathrm{c}}$ calculated from Eq. (3). This means that the Faraday efficiency, $\eta_{\mathrm{F}}$, in our calculations is equal to 1. Experimental data from [10] show that the Faraday efficiency is close to 1 at higher current densities. These conditions were also confirmed during experiments.

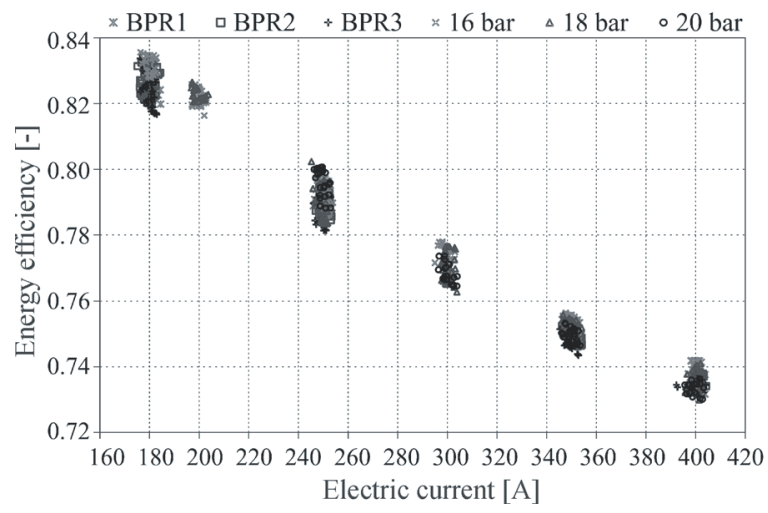

Fig. 6. Energy efficiency of an electrolytic cell at typical operating conditions

The results from both experiments (BPRi and $p_{\text {CONST }}$ ) show that the energy efficiency of an electrolytic cell at typical operating conditions is between 73 and $83 \%$, where higher electric current corresponds to lower energy efficiency (Fig. 6).

Because of the system and experimental setup limitations, the energy efficiency of an electrolytic cell is, in our case, equal to the energy efficiency of the cell stack, [12].

\subsection{Empirical I - U Model}

For the evaluation of different operating pressures on the performance of the electrolyser cell stack, the following empirical current-voltage $(I-U)$ relationship was used, [10]:

$$
U_{\text {op }}=U_{\text {rev }} \cdot \mathrm{r}_{1} \frac{I}{A}+\mathrm{r}_{2} \cdot \ln \left(\mathrm{r}_{3} \cdot \frac{I}{A}+1\right),
$$

where $r_{1}, r_{2}$ and $r_{3}$ are parameters, in general depended on operating temperature and pressure. The ratio $I / A$ represents current density $(j)$ :

$$
j=\frac{I}{A},
$$

where $A$ is an electrode area.

The results presented in Fig. 7 and Table 1 show that the operating pressure between 16 and 20 bar $\mathrm{g}$ has no significant influence on the electrolyser cell stack performance. Experimental data for this analysis were collected during the pCONST experiment.

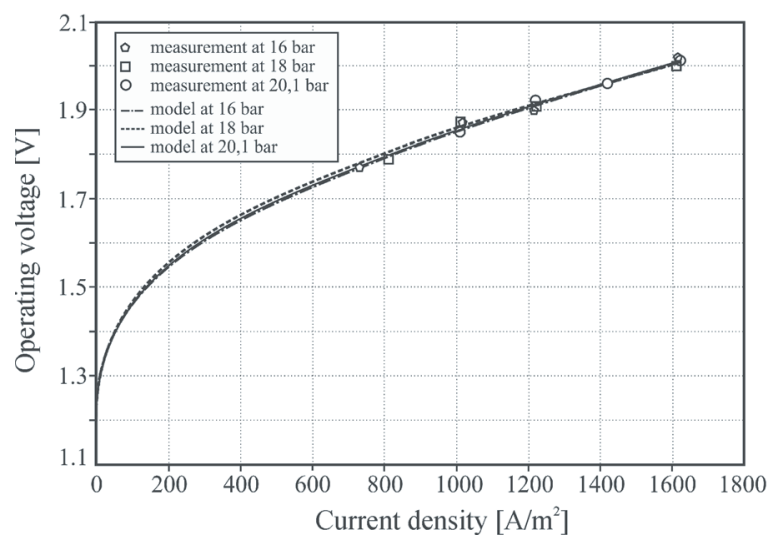

Fig. 7. I - U curves for different operating pressures

Table 1. Operating conditions and values of parameters in the empirical I - U model

\begin{tabular}{ccccc}
\hline \multicolumn{2}{c}{ Operating condition } & \multicolumn{3}{c}{ Parameter } \\
\hline $\mathrm{p}[\mathrm{bar} \mathrm{g}]$ & $\mathrm{T}\left[{ }^{\circ} \mathrm{C}\right]$ & $\mathrm{r}_{1} \cdot 10^{-3}[\mathrm{Vm} 2 / \mathrm{A}]$ & $\mathrm{r}_{2}[\mathrm{~V}]$ & $\mathrm{r}_{3}\left[\mathrm{~m}^{2} / \mathrm{A}\right]$ \\
\hline 16.0 & 61.4 & 0.17893 & 0.10175 & 0.10164 \\
\hline 18.0 & 62.1 & 0.16484 & 0.10485 & 0.10431 \\
\hline 20.1 & 62.5 & 0.17795 & 0.10216 & 0.10235 \\
\hline
\end{tabular}

Fig. 8 also presents results from the BPRi experiments, including experimental data in the pressure range between 15 and 21 bar g, which further confirm that the performance of the electrolyser cell stack is not influenced by the operating pressure in this (extended) pressure range.

According to experimental data from [10], in addition to electric current, operating (electrolyte) temperature has a significant influence on the alkaline water electrolysis process. However, in our case, electrolyte temperature could not be changed, since it is locked by the manufacturer. Nevertheless, its influence can be evaluated indirectly from experimental data obtained at a constant electric current before the beginning of the BPRi experiment (Fig. 9). 


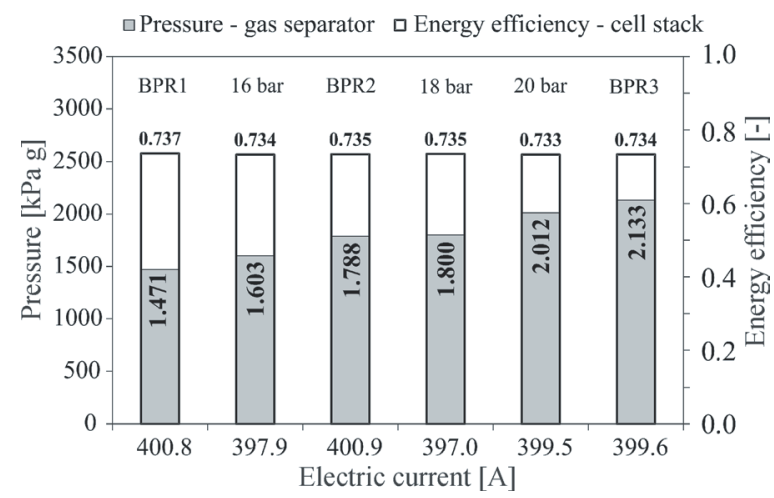

Fig. 8. Energy efficiency of the cell stack at constant electric current and different operating pressures

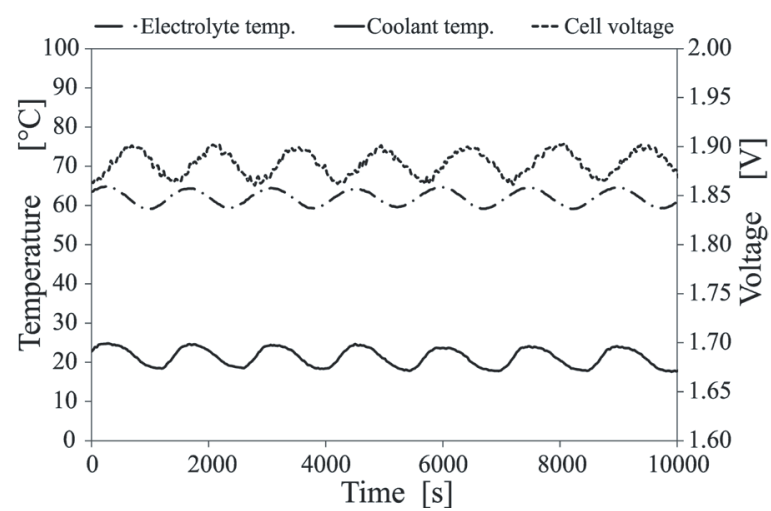

Fig. 9. Operating (cell) voltage, electrolyte temperature and coolant temperature at constant electric current as a function of time

In Fig. 9, it can be observed that by operating the electrolyser at constant electric current for a longer period of time the electrolyte temperature tends to follow the sinusoidal behaviour of the coolant temperature as a result of the operating characteristics of the cooling system. Furthermore, it can be seen that operating (cell) voltage varies with the same frequency as the electrolyte temperature, but with some phase shift. The phase shift is approximately equal to $\pi$, which means that the operating voltage reaches its minimum value when the electrolyte temperature is approximately at the maximum value. This observation corresponds to the experimental data from [10] that indicates that higher operating temperatures have a favourable effect on the process of water electrolysis, since a lower operating voltage results in higher energy efficiency (Eq. (11)). The results presented in Fig. 10 confirm that the variation (sinusoidal oscillation) in voltage and consequently in the energy efficiency of an electrolytic cell is a result of the variation of electrolyte temperature and not of the electric current.

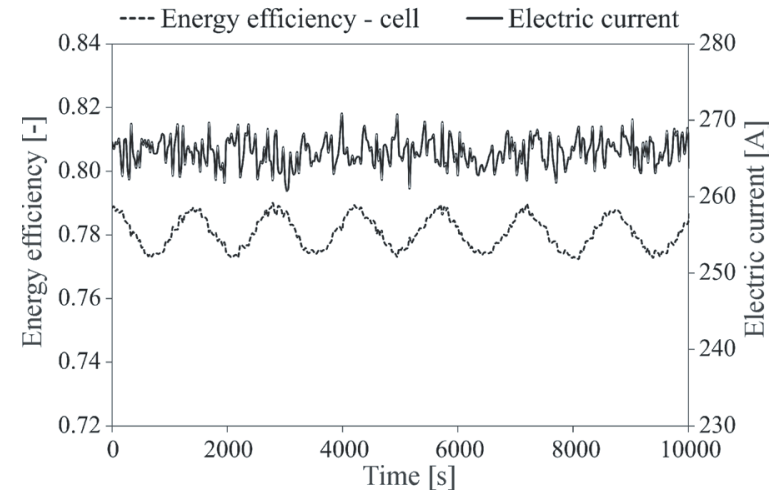

Fig. 10. Energy efficiency and electric current as a function of time (at constant electric current)

The electrolyte temperature and consequent energy efficiency of the cell could be more constant if the difference between regulation temperatures that turn on/shut off the cooling system of the electrolyte would be smaller. Because the manufacturer locked those settings, we could not test them. Another possibility to obtain more constant electrolyte temperature is to implement a different coolant system with evaporation cooling in which temperature of the coolant is constant.

\subsection{Energy Efficiency of the Entire System}

The energy efficiency of the entire system can be defined as:

$$
\eta=\frac{\dot{H}_{\mathrm{H}_{2}}}{P_{\text {ele }}}=\frac{\delta \cdot \dot{m}_{\mathrm{H}_{2}}\left(t_{\mathrm{m}}\right) \cdot H_{\mathrm{S}, \mathrm{H}_{2}}}{P_{\text {ele }}},
$$

where $\delta$ is the purity of hydrogen leaving the system, $\dot{m}_{\mathrm{H} 2}\left(t_{\mathrm{m}}\right)$ represents the average mass flow of hydrogen leaving the system and $P_{\text {ele }}$ is the electric power input of the entire system. $P_{\text {ele }}$ is determined as the amount of electric energy consumed during the time of the experiment:

$$
P_{\text {ele }}=\frac{W_{\text {ele }}\left(t_{\mathrm{m}}\right)-W_{\text {ele }}(0)}{t_{\mathrm{m}}},
$$

and the average mass flow of hydrogen leaving the system is calculated according to this gas law:

$$
\dot{m}_{\mathrm{H}_{2}}\left(t_{\mathrm{m}}\right)=\frac{V_{\text {tank }}}{t_{\mathrm{m}} \cdot R_{\mathrm{H}_{2}}} \cdot\left(\frac{p_{\mathrm{H}_{2}}\left(t_{\mathrm{m}}\right)}{T_{\text {tank }}\left(t_{\mathrm{m}}\right)}-\frac{p_{\mathrm{H}_{2}}(0)}{T_{\text {tank }}(0)}\right) .
$$

The energy efficiency of the system is calculated on the basis of the gas law for ideal gases, since there 
is no direct measurement of hydrogen mass flow in the system. On the basis of the measured data and project documentation (volume of the hydrogen storage tank), the calculation was done for a longer period of hydrogen production to minimise the error of the calculated mass flow of hydrogen leaving the system. The results of the measurements show that the (average) energy efficiency of the entire system during the BPRi measurement set was 56.5 $\pm 4.2 \%$; during the $p_{\text {CONST }}$ measurement set, it was $54.6 \pm 3.9 \%$ (Table 2). Differences in efficiency are in principle due to higher losses of hydrogen in the second set of measurements, which corresponds to the higher operating pressure in the system, although during this experiment the average electric current was lower (Table 2), resulting in the higher energy efficiency of an electrolytic cell. The relatively high measuring uncertainty $( \pm 4 \%)$ is due to the mass flow calculation on the basis of gas law that was (in this case) the only possibility of indirectly measuring the mass flow of hydrogen leaving the system.

\subsection{Hydrogen Losses within the Boundaries of the System}

Because of the specific design of the analysed alkaline water electrolysis system, also presented in Section 2, a portion of the produced hydrogen is used for system conditioning, resulting in hydrogen losses in the atmosphere. The hydrogen losses $(\xi)$ are calculated on the basis of the following equation:

$$
\xi=1-\frac{\delta \cdot \dot{m}_{\mathrm{H}_{2}}\left(t_{\mathrm{m}}\right)}{\eta_{\mathrm{F}} \cdot N \cdot \dot{m}_{\mathrm{H}_{2}, \mathrm{c}}\left(t_{\mathrm{m}}\right)} n,
$$

where $N$ is the number of electrolytic cells in the cell stack. Since the average mass flow of hydrogen leaving the system is calculated according to gas law, calculations are performed for a longer period of hydrogen production.

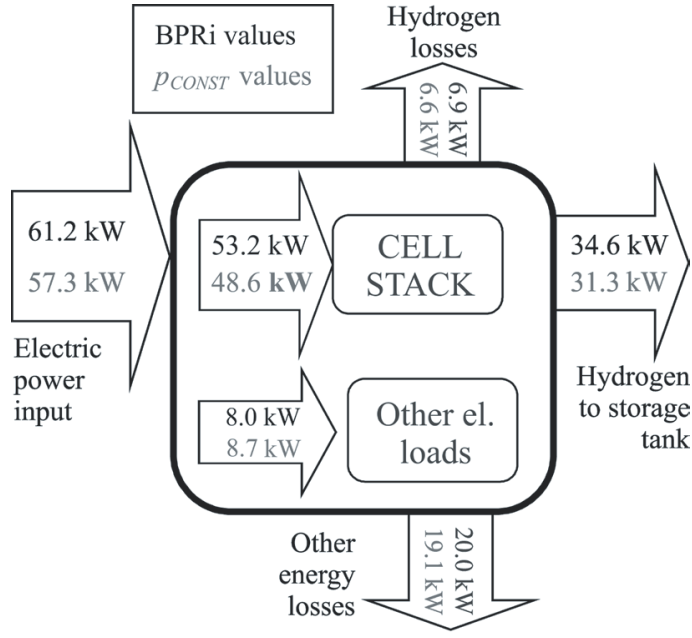

Fig. 11. Energy flows within the system boundaries

Results show that (average) hydrogen losses within the boundaries of the system were equal to $16.1 \pm 6.5 \%$ in the BPRi experiment setup and $18.1 \pm 6.2 \%$ in the $p_{\text {CONST }}$ experiment setup (Table 2 ). Higher hydrogen losses in the $p_{\text {CONST }}$ experiment (up to $2 \%$ ) are due to higher operating pressure in the system. At higher operating pressures, more hydrogen is needed to fill the 'Fill Up Volume' (Fig. 4) for conditioning the system; consequently, losses of hydrogen are higher.

On the basis of performed calculations, the average energy flows within the system boundaries for both major sets of measurements (experiment BPRi and $\left.p_{\text {CONST }}\right)$ are presented in Fig. 11. It can be seen that hydrogen losses converted into energy flow represent a relatively high value; therefore, a question arises of whether a design of the system with a demineralised water feed pump would have a more favourable impact on the energy efficiency of the entire system.

\section{CONCLUSIONS}

The integration of systems based on renewable energy sources (mainly photovoltaics, wind and small hydropower plants) into the existing electricity infrastructure is necessarily associated with the

Table 2. Average values for operating conditions, energy efficiencies and hydrogen losses for both experiments ( $U$ * is expanded uncertainty with expansion factor $k=2$ )

\begin{tabular}{cccccccccc}
\hline & \multicolumn{3}{c}{ Operating conditions } & \multicolumn{3}{c}{ Energy efficiency } & \multicolumn{3}{c}{$\mathrm{H}_{2}$ losses } \\
\hline & $\mathrm{I}[\mathrm{A}]$ & $\mathrm{p}[\mathrm{bar} \mathrm{g}]$ & $\mathrm{T}\left[{ }^{\circ} \mathrm{C}\right]$ & $\eta[\%]$ & $\mathrm{U}^{*}$ & $\eta_{\mathrm{c}}[\%]$ & $\mathrm{U}^{*}$ & $\xi[\%]$ & $\mathrm{U}^{*}$ \\
\hline BPRi & 308.3 & 16.9 & 63.1 & 56.5 & \pm 4.2 & 77.24 & \pm 0.29 & 16.1 & \pm 6.5 \\
\hline$p_{\text {CONST }}$ & 286.0 & 17.6 & 61.6 & 54.6 & \pm 3.9 & 78.11 & \pm 0.27 & 18.1 & \pm 6.2 \\
\hline
\end{tabular}


development of energy storage systems. One possible solution is to store electrical energy in the internal energy of hydrogen through the electrolysis of water.

A commercial alkaline electrolyser was analysed in detail regarding the energy efficiency of an electrolytic cell, the energy efficiency of the entire system and hydrogen losses within the boundaries of the system. In addition, the parameters of an empirical model that presents electrolyser characteristics, i.e. voltage vs. electric current (current density) dependency, were determined on the basis of experimental data. The results show that:

- The energy efficiency of an electrolytic cell at typical operating conditions is between 73 and $83 \%$, where higher electric current corresponds to lower energy efficiency.

- The operating pressure between 16 and 20 bar g has no significant influence on the electrolyser cell stack performance. The electrolyser characteristics also show that higher hydrogen production is always linked with higher energy losses.

- In addition to electric current, operating (electrolyte) temperature has a significant influence on the alkaline water electrolysis process. The variation of temperature in the range between 59 and $65{ }^{\circ} \mathrm{C}$ at constant electric current $(266 \mathrm{~A})$ leads to a variation of the energy efficiency of an electrolytic cell in the range between 77 and $79 \%$, where higher temperature corresponds to higher energy efficiency.

- The calculated overall (average) energy efficiency of the system on the basis of experimental data is in the range between 50 and $60 \%$. The results suggest that the energy efficiency of the entire system depends on the operating pressure, where higher operating pressure corresponds to higher hydrogen losses within the boundaries of the system and consequently lower energy efficiency.

- During the experiments, (average) hydrogen losses within the boundaries of the system ranged between 10 and $25 \%$. Hydrogen losses converted into energy flows represent a relatively high value $(\sim 7 \mathrm{~kW})$; therefore, a question arises of whether the design of the system with a demineralised water feed pump would have a more favourable impact on the overall energy efficiency of the system.

The analysed commercial alkaline electrolyser is able to adapt relatively quickly to new operating conditions even if the electric current or/and system pressure changes significantly. However, operating the electrolyser at variable operating conditions has a negative impact on the purity of the produced gases and the energy efficiency of the entire system.

\section{ACKNOWLEDGEMENTS}

Part of this work was carried out within the Centre of Excellence for Low-Carbon Technologies (CO NOT), Hajdrihova 19, 1000 Ljubljana, Slovenia.

\section{NOMENCLATURE}

$\begin{array}{lll}A & \text { electrode surface } & {\left[\mathrm{m}^{2}\right]} \\ a & \text { characteristic constant } \\ b & \text { characteristic constant } \\ F & \text { Faraday constant } & {[\mathrm{As} / \mathrm{mol}]} \\ G & \text { Gibbs energy } & {[\mathrm{J}]} \\ H & \text { enthalpy } & {[\mathrm{J}]} \\ H_{\mathrm{S}} & \text { higher heating value } & {[\mathrm{kJ} / \mathrm{kg}],[\mathrm{kJ} / \mathrm{kmol}]} \\ \dot{H} & \text { enthalpy flow } & {[\mathrm{W}]} \\ I & \text { electric current } & {[\mathrm{A}]} \\ j & \text { current density } & {\left[\mathrm{A} / \mathrm{m}^{2}\right]} \\ k & \text { expansion factor } & \\ M & \text { molar mass } & {[\mathrm{g} / \mathrm{mol}],[\mathrm{kg} / \mathrm{kmol}]} \\ \dot{m} & \text { mass flow } & {[\mathrm{kg} / \mathrm{s}]} \\ N & \text { number of electrolytic cells } \\ P & \text { electric power } & {[\mathrm{W}]} \\ p & \text { pressure } & {[\mathrm{Pa}],[\mathrm{bar}]} \\ R & \text { electric resistance } & {[\Omega]} \\ R & \text { gas constant } & {[\mathrm{J} /(\mathrm{kg} \mathrm{K})]} \\ \mathrm{r} & \text { constant in } I-U \text { empirical model } \\ S & \text { entropy } & {[\mathrm{J} / \mathrm{K}]} \\ T & \text { temperature } & {[\mathrm{K}],\left[{ }^{\circ} \mathrm{C}\right]} \\ t & \text { time } & {[\mathrm{s}],[\mathrm{min}]} \\ U & \text { electric voltage } & {[\mathrm{V}]} \\ U & \text { expanded uncertainty } \\ V & \text { volume } & {\left[\mathrm{m}{ }^{3}\right]} \\ W & \text { energy } & {[\mathrm{J}]} \\ \bar{x} & \text { arithmetic mean } & \\ z & \text { number of moles of electrons } \\ & & \end{array}$

\section{GREEK SYMBOLS}

$\triangle$ difference

$\delta \quad$ hydrogen purity

$\eta \quad$ energy efficiency

$v_{\mathrm{e}}$ stoichiometric coefficient

$\xi \quad$ hydrogen losses

c electrolytic cell

\section{SUBSCRIPTS \\ el electrode \\ ele electric \\ F Faraday \\ $\mathrm{H}_{2}$ hydrogen}




$\begin{array}{ll}\mathrm{m} & \text { measurement } \\ \text { ohm } & \text { ohmic } \\ \text { op } & \text { operating } \\ \mathrm{p} & \text { product } \\ \text { rev } & \text { reversible } \\ \mathrm{t} & \text { time } \\ \text { tank } & \text { tank } \\ \text { tn } & \text { thermo-neutral }\end{array}$

\section{REFERENCES}

[1] Asmus, P. (2010). Microgrids, virtual power plants and our distributed energy future. The Electricity Journal, vol. 23, no. 10, p. 72-82, DOI:10.1016/j. tej.2010.11.001.

[2] Hammons, T.J. (2008). Integrating renewable energy sources into European grids. International Journal of Electrical Power and Energy Systems, vol. 30, no. 8, p. 462-475, DOI:10.1016/j.ijepes.2008.04.010.

[3] Pirc, A., Sekavčnik, M., Drobnič, B., Mori, M. (2011). Use of hydrogen technologies for saving electric energy in combination with renewable energy systems. $6^{\text {th }}$ International Workshop on Deregulated Electricity Market Issues in South-Eastern Europe, Demsee.

[4] Tuma, M., Sekavčnik, M. (2004): Energy Systems: Distribution of Electrical and Heat Energy. University of Ljubljana, Faculty of Mechanical Engineering, Ljubljana.

[5] Sekavčnik, M., Mori, M., Grilc, V., Gajzer, M., Mešl, M., Koplan, F. (2008). SPEV - Slovenia and Transition to Hydrogen Economy - SPEV : Final Report of Research Project: October 2008: CRP Competitive Position of Slovenia 2006-2013, University of Ljubljana, Faculty of Mechanical Engineering, Ljubljana.
[6] Center of excellence for low carbon technologies - CO NOT, from: http://www.conot.si/index.php/ razvojni-programi/102-rrp-9-demonstracijski-projekt2-vodikove-tehnologije-v-napredni-energetski-oskrbi. html, accessed at 2012-12-12.

[7] Barbaro, P., Bianchini, C. (2009). Catalysis for Sustainable Energy Production. Wiley-VCH Verlag KGaA, Weinheim.

[8] Lazarini, F., Brenčič, J. (2004). General and Inorganic Chemistry: University Textbook. DZS, Ljubljana.

[9] Wendt, H., Kreysa, G. (1999). Electrochemical Engineering: Science and Technology in Chemical and Other Industries. Springer-Verlag, Berlin, Heidelberg, New York.

[10] Ulleberg, Ø. (2003). Modeling of advanced alkaline electrolyzers: a system simulation approach. International Journal of Hydrogen Energy, vol. 28, no. 1, p. 21-33, DOI:10.1016/S0360-3199(02)00033-2.

[11] Grimes, C.A., Varghese, O.K., Ranjan, S. (2008). Light, Water, Hydrogen: The Solar Generation of Hydrogen by Water Photoelectrolysis. Springer Science+ Business Media, New York.

[12] Mržljak, T. (2011). Electrolyzer Within Distributed Power Generation System. Master thesis, University of Ljubljana, Faculty of Mechanical Engineering, Ljubljana.

[13] Kreuter, W., Hofmann, H. (1998). Electrolysis: The important energy transformer in a world of sustainable energy. International Journal of Hydrogen Energy, vol. 23, no. 8, p. 661-666, DOI:10.1016/S03603199(97)00109-2.

[14] Zeng, K., Zhang, D. (2010). Recent progress in alkaline water electrolysis for hydrogen production and applications. Progress in Energy and Combustion Science, vol. 36, no. 3, str. 307-326, DOI:10.1016/j. pecs.2009.11.002. 